\title{
Accuracy Investigation of Features Produced by Additive Technology
}

\author{
Katarina Monkova ${ }^{1, *}$ and Peter Monka ${ }^{1,2}$ \\ ${ }^{1}$ Technical university of Kosice, Faculty of manufacturing technologies with the seat in Presov, Presov, Slovakia \\ ${ }^{2}$ University of West Bohemia, Faculty of Mechanical Engineering, Pilsen, Czech Republic \\ *Corresponding author
}

\begin{abstract}
The article deals with investigation of accuracy of shaped features produced by additive technology. Within the study, a complex component was designed so to include many specific geometrical features that represent the most used shaped units of technical parts. During presented research, deviations from nominal positions and deviation of profile shape were investigated in individual points of part. In accordance with prediction, the results have shown various values of deviations from nominal dimensions in comparison to ideal shape of part. The inaccuracies could be caused by the changes in temperature at the building of individual layers what could influence a deformation and stress of the part. On the other hand, the achieved results in this research were probably influenced also by orientation of the part, that was selected during production, and by the related position of supports which were necessary to build so to be designed part self-supporting.
\end{abstract}

Keywords-deviation; nominal value; geometrical features; additive technology

\section{INTRODUCTION}

DMLS is the preferred method of 3D rapid prototyping for complex geometries. As the additive manufacturing process is very complex, logically, there exist some obstacles and problems that prevent the formation of high quality parts. A thermal gradient of the material can cause an inner stress along with shrinkage which consequently influences precision of the part. The shrinkage is strongly influenced by technological parameters, building temperature, the temperature in the working chamber, a cooling rate etc. Crystalline shrinkage which occur during cooling, can be in different directions very heterogeneous, it can thus occur to a large expansion of shrinkage during the time course of sintering.

During manufacturing of simple components, it is generally preferable and especially cheaper to use the classical conventional methods. The intensity of production increases along with the complexity of the part at the conventional production methods. Likewise, there are greater demands for production times, necessary machinery and tools, for operator qualification etc. In $3 \mathrm{D}$ printing it is vice versa, because the production of simple components takes the same time as the production of complex parts. Moreover, it is possible to produce the different components in a single operation at the same machine. The production is extended only in the case, if the material will be applied in thinner layers due to better quality of part. [1,2]
The most restrictive parameters of $3 \mathrm{D}$ printing are: construction materials, production speed, cost, accuracy. During laser sintering it occurs to change in temperature and state of the material what often causes a deformation and stress of the part, which is very difficult to remove. One solution of this problem is to preheat and reheat the manufacturing process It is not possible to remove these effects completely, but only to reduce them. Other limitations include the inaccuracy which is caused by the thickness of the built layer. [3]

An important part of the preparatory process, which directly affects the productivity and quality components, is an orientation. On the curved and inclined surfaces often appears so called staircase effect, that negative effects their dimensional accuracy. Unfortunately, there is no way to completely eliminate the staircase effect. A better result can be achieved by reducing the thickness of the individual layers. At this stage, the designer has to specify how the part will be positioned inside the workspace. The orientation of the component has a great influence on its accuracy, surface quality, construction time, the required number of support structures and also on the production costs. [4,5]

To solve this problem, a number of studies was done. For example, Allen and Dutta [6] have developed a method for automatic calculation of load-bearing structures and a decision method to select the most appropriate orientation.

Masood and Rattanawong [7] developed an algorithm for calculating the size of volumetric error that is caused by cutting the CAD model. Volumetric errors are calculated for different orientations turning around user-specified axes. The best orientation is then determined as the part with a minimum density error.

Frank and Fadel [8] designed an expert system, which takes into account various parameters that affect the production of components. This system works with the specified input parameters and created decision matrix according to which the system recommends the best direction and orientation of the building components in the workspace.

Mr. Pham et al. [9] developed a support tool for decision making that helps users determine the proper orientation of the part. There are works with a variety of factors, such as construction time, production costs, the problematic features of the component (hole axis, critical surfaces etc.), overhanging ends, volume aids etc. To the individual criteria, it is intuitively allocated scoring that is multiplied by points assigned to each 
version of orientation. Orientation, which gets the most scoring is most suitable for the orientation of the components in the workspace.

Researchers Hur, Choi, Lee and Chang [10] developed an algorithm to calculate the stair effect. Its task was to quantify procedural errors by the volume of material, which has to be removed or added to the components. In addition, it is able to quantify the total assembly time and the volume of the structure.

Usually constant thickness of the layer is kept. The parameters changing during production is rarely. However, when creating a part with a constant layer thickness leads to certain drawbacks. It is likely that the components will miss small features and details. In addition, a constant film thickness can in-crease assembly time, because continuous application of a minimum layer is required to meet the requirement for surface roughness. If applied in varying thickness, some of the problems mentioned above could be reduced. [11,12]

\section{COMPONENT Design AND Methods OF INVESTIGATION}

During selective laser sintering a large amount of stress is accumulated in the built structures. This adverse phenomenon is the result of rapid heating and subsequent cooling, which is detrimental to mechanical properties of the components. In case the printed part it is not possible to cool in a controlled environment for the necessary period, the part has a tendency for a faster cooling. Rapid cooling can cause significant stress which can result to deformation of components. [13,14,15]

Authors dealt with the process of shrinkage in the production of metal parts using additive technology. Since the shrinkage is needed to examine different nominal lengths, so even a sample should contain different lengths.

To investigate the qualitative parameters of the part produced by 3D metal printing technology, the special component with many problematic and specific features (holes, ribs, tapered surfaces, grooves, shaped cuts ...) was designed. Designed part is thin-walled cubic with sizes $70 \times 70 \times 70 \mathrm{~mm}$ and thickness of $2 \mathrm{~mm}$. Its top shape includes two types of ribs (wavy and beveled) with height of $5 \mathrm{~mm}$, width in range from 0.15 to $0.8 \mathrm{~mm}$ and angles from $37^{\circ}$ to $60^{\circ}$. Dominant feature of inner surface of the cube is sphere with diameter of $44 \mathrm{~mm}$. Virtual model of the part is shown in Figure 1. [16]

The ribs were designed due to the confirmation (or negation) a theory according to which it is not possible to build a wall up to angle $40^{\circ}$ without supports. [17]
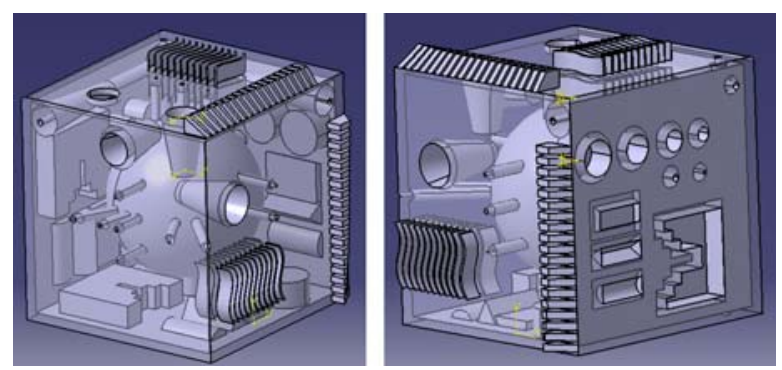

FIGURE I. VIRTUAL MODEL OF THE PART [16]
The designed part also includes many holes in various axis directions with diameters from 1 to $10 \mathrm{~mm}$, conical holes and various types of grooves (triangle, trapezoidal and with radius). There are also holes with various thickness of the wall and acicular juts in various axis and slant.

The part was produced from steel 1.2709, which is characterized by good usage at higher ambient temperatures. Chemical composition and mechanical properties of the steel are presented in Table I. [18]

TABLE I. CHEMICAL COMPOSITION AND MECHANICAL POPERTIES OF STEEL 1.2709 [18]

\begin{tabular}{|c|c|c|c|c|c|c|c|}
\hline $\mathrm{C}[\%]$ & $\mathrm{Cr}[\%]$ & Mo [\%] & $\mathrm{Ni}[\%]$ & Co [\%] & \multicolumn{2}{|c|}{$\mathrm{Ti}[\%]$} & $\mathrm{Si}[\%]$ \\
\hline$<0.03$ & $<0.3$ & $4.5-5.2$ & $17-19$ & $7-9$ & \multicolumn{2}{|c|}{$0.8-1.2$} & $<0.1$ \\
\hline & \multicolumn{4}{|c|}{ Hardness [HRC] } & & \multicolumn{2}{|c|}{$35-40$} \\
\hline & \multicolumn{4}{|c|}{ Yield strength $\left[\mathrm{Nmm}^{-2}\right]$} & & \multicolumn{2}{|c|}{950} \\
\hline & \multicolumn{5}{|c|}{ Compressive strength $\left[\mathrm{Nmm}^{-2}\right]$} & \multicolumn{2}{|c|}{1100} \\
\hline & \multicolumn{5}{|c|}{ Elongation $[\%]$} & \multicolumn{2}{|r|}{4} \\
\hline & \multicolumn{5}{|c|}{ Elastic modulus $\left[10^{3} \mathrm{Nmm}^{-2}\right]$} & \multicolumn{2}{|c|}{200} \\
\hline & \multicolumn{5}{|c|}{ Thermal conductivity $[\mathrm{W} / \mathrm{mK}]$} & \multicolumn{2}{|c|}{21} \\
\hline
\end{tabular}
[16]

Basic views on manufactured part are displayed in Figure II.

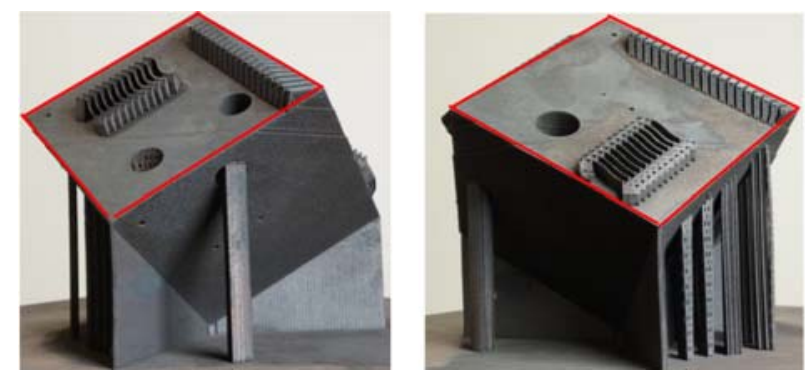

FIGURE II. PRODUCED PART WITH SUPPORTS [16]

The parameters that characterize precision of produced features were investigated direct after production and also after heat treatment. The measures were done by contact method at which measured characteristics were compared with nominal sizes. Measuring equipment CZ Prismo Navigator of company ZEISS (Figure III.) was used. It is a high-speed measuring machine that works with an accuracy of $0.05 \mathrm{~mm}$.

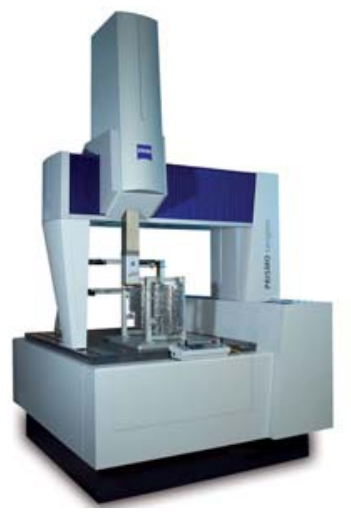

FIGURE III. MEASURING EQUIPMENT CZ PRISMO NAVIGATOR 
To carry out the measures, it was necessary to create a part network of points at which deviations from the ideal size were subsequently measured. Since the part was aligned to one of the corners, it was possible to measure only three top surfaces of, because bottom surfaces of the sample were built by means of supports as it can be seen in Figure IV. [16]
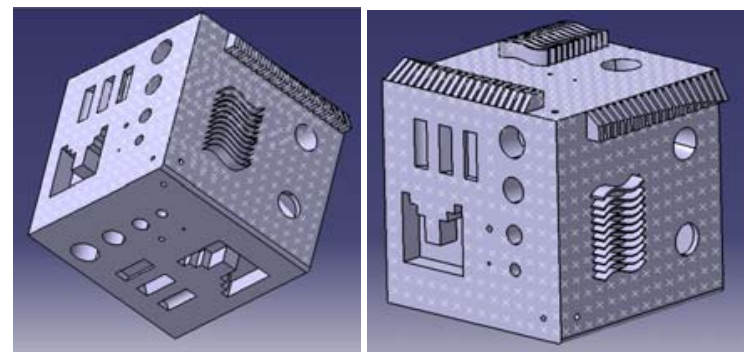

FIGURE IV. NETWORK OF POINTS [16]

When designing the network, it had to be taken into account the size of the probe. Points had to be spaced at least $2 \mathrm{~mm}$ from the edge of the cube and their mutual distance had to be at least $5 \mathrm{~mm}$. These measurements enable to monitor planarity, shape of various surfaces, accuracy of the angles and further individual grooves, accuracy of circular holes and angles in tapered holes.

\section{RESUlTS AND DisCUSSION}

As it was said, measures were carried out on features positioned on three surfaces. Deviation from nominal dimensions and deviation of the profile shape were measured. All measures were done in three steps. The first step (first set of measures) was done after laser sintering, where the produced part was connected with base and supports. The second measure was realized after heat treatment (heating on $540{ }^{\circ} \mathrm{C}$, this temperature was maintained for 6-8 hours, rates of heating and cooling were the same $100{ }^{\circ} \mathrm{C} / \mathrm{h}$ ). The last set of measures was done after supports removing. The example of achieved results of deviation from ideal model dimensions measured in designed network points is presented in Figure V. [16] Next measured values are listed in Tables II. - IV. [16]
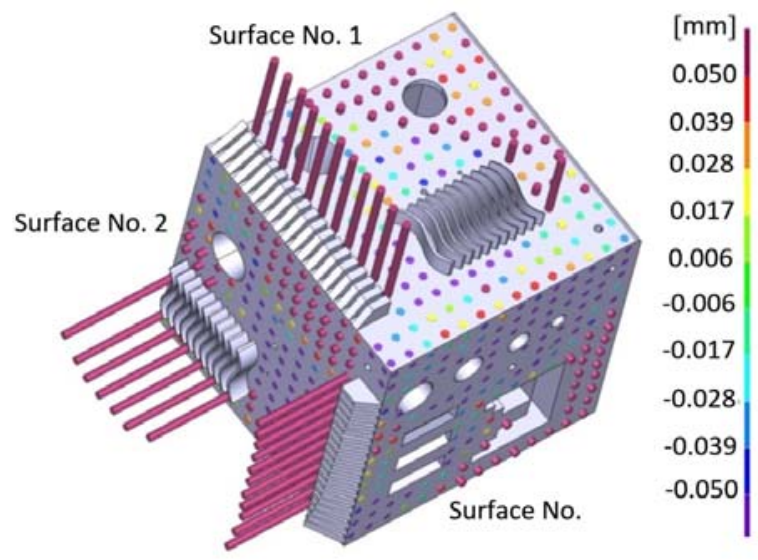

FIGURE V. PRESENTATION OF MEASURED DEVIATIONS FROM NOMINAL VALUES
TABLE II. SURFACE NO. 1

\begin{tabular}{|c|c|c|c|c|c|}
\hline \multirow{3}{*}{$\begin{array}{l}\text { Type of the } \\
\text { measure }\end{array}$} & \multirow{3}{*}{ Measured feature } & \multirow{3}{*}{$\begin{array}{c}\text { Nominal } \\
\text { dimension }\end{array}$} & \multicolumn{3}{|c|}{ Surface No. 1} \\
\hline & & & \multicolumn{3}{|c|}{ Measure } \\
\hline & & & 1st & 2nd & 3rd \\
\hline \multirow{12}{*}{$\begin{array}{c}\text { Deviation from } \\
\text { nominal } \\
\text { dimension }\end{array}$} & \multirow{10}{*}{ Bevelled ribs $\left[{ }^{\circ}\right]$} & 60 & 0.140 & 0.022 & $0.033^{\circ}$ \\
\hline & & 56 & 0.340 & 0.295 & $0.190^{\circ}$ \\
\hline & & 52 & 0.328 & 0.371 & $0.338^{\circ}$ \\
\hline & & 49 & 0.288 & 0.189 & $0.141^{\circ}$ \\
\hline & & 47 & 0.173 & 0.259 & $0.234^{\circ}$ \\
\hline & & 45 & 0.503 & 0.458 & $0.451^{\circ}$ \\
\hline & & 43 & 0.315 & 0.400 & $0.325^{\circ}$ \\
\hline & & 41 & 0.484 & 0.501 & $0.633^{\circ}$ \\
\hline & & 39 & 0.293 & 0.553 & $0.600^{\circ}$ \\
\hline & & 37 & 0.329 & 0.414 & $0.510^{\circ}$ \\
\hline & Conical hole $\left[{ }^{\circ}\right]$ & 20 & -0.182 & -0.564 & -0.514 \\
\hline & $\begin{array}{c}\text { Diameter of } \\
\text { circular hole [mm] }\end{array}$ & 10 & 0.134 & 0.161 & 0.179 \\
\hline $\begin{array}{l}\text { Deviation of the } \\
\text { profile shape }\end{array}$ & Wavy ribs [mm] & 0.000 & 0.206 & 0.130 & 0.138 \\
\hline
\end{tabular}

TABLE III. SURFACE NO. 2

\begin{tabular}{|c|c|c|c|c|c|}
\hline \multirow{3}{*}{$\begin{array}{l}\text { Type of the } \\
\text { measure }\end{array}$} & \multirow{3}{*}{ Measured feature } & \multirow{3}{*}{$\begin{array}{c}\text { Nominal } \\
\text { dimension }\end{array}$} & \multicolumn{3}{|c|}{ Surface No. 2} \\
\hline & & & \multicolumn{3}{|c|}{ Measure } \\
\hline & & & $1 \mathrm{st}$ & 2nd & 3 rd \\
\hline \multirow{11}{*}{$\begin{array}{c}\text { Deviation from } \\
\text { nominal } \\
\text { dimension }\end{array}$} & \multirow{10}{*}{ Bevelled ribs $\left[{ }^{\circ}\right]$} & 60 & 0.281 & 0.217 & $0.276^{\circ}$ \\
\hline & & 56 & 1.208 & 1.020 & $0.018^{\circ}$ \\
\hline & & 52 & 0.122 & 0.134 & $0.020^{\circ}$ \\
\hline & & 49 & 0.387 & 0.232 & $0.188^{\circ}$ \\
\hline & & 47 & 0.014 & 0.539 & $0.425^{\circ}$ \\
\hline & & 45 & -0.773 & -0.900 & $-0.931^{\circ}$ \\
\hline & & 43 & 0.117 & 0.193 & $0.437^{\circ}$ \\
\hline & & 41 & -0.985 & -0.536 & $-0.608^{\circ}$ \\
\hline & & 39 & -0.758 & -0.511 & $-0.602^{\circ}$ \\
\hline & & 37 & 0.338 & 0.337 & $0.167^{\circ}$ \\
\hline & Conical hole $\left[{ }^{\circ}\right]$ & 20 & -0.014 & -0.282 & -0.200 \\
\hline $\begin{array}{l}\text { Deviation of the } \\
\text { profile shape }\end{array}$ & Wavy ribs [mm] & 0.000 & 0.606 & 0.579 & 0.476 \\
\hline
\end{tabular}

TABLE IV. SURFACE NO. 3

\begin{tabular}{|c|c|c|c|c|c|}
\hline \multirow{3}{*}{$\begin{array}{l}\text { Type of the } \\
\text { measure }\end{array}$} & \multirow{3}{*}{ Measured feature } & \multirow{3}{*}{$\begin{array}{c}\text { Nominal } \\
\text { dimension }\end{array}$} & \multicolumn{3}{|c|}{ Surface No. 3} \\
\hline & & & & Measur & \\
\hline & & & 1st & 2nd & 3 rd \\
\hline \multirow{5}{*}{$\begin{array}{c}\text { Deviation } \\
\text { from } \\
\text { nominal } \\
\text { dimension }\end{array}$} & \multirow{2}{*}{$\begin{array}{l}\text { Diameter of circular hole } \\
{[\mathrm{mm}]}\end{array}$} & 10 & -0.026 & -0.032 & -0.039 \\
\hline & & 8 & -0.001 & -0.023 & -0.026 \\
\hline & Triangle grove $\left[{ }^{\circ}\right]$ & 60 & -0.001 & -0.001 & -0.001 \\
\hline & Grove with radius [mm] & 2.5 & -0.118 & -0.125 & -0.126 \\
\hline & Width of Stair grove [mm] & 24 & -0.097 & -0.137 & -0.123 \\
\hline
\end{tabular}

Based on the obtained results it is not possible exactly to say what type of modifications (heat treatment, removal of supports) had the greatest impact on the part, because values of different features considerably varied. Deviations from nominal values of some features gradually increased, at other were decreasing and in some cases their course was fluctuated. From Figure 5 it can be seen on Surface No.1 that the values of deviations are increasing in diagonal direction from negative values to positive. At detailed study of the part orientation it is possible to notice that time of layers building is longer in the corner with negative values of deviation and there is formed some kind of excess in this area. In despite of the fact that component was sufficiently supported, the supports apparently were not able to maintain the component perfectly, so there occurs to the formation of significant errors at area of this overhang. Significant deviations from nominal values of beveled ribs are caused by the existence of support structures, 
which joined to the bottom wall of cube during sintering, what has affected positions of observed points. The same situation was at wavy ribs. Similar to the Surface No. 1, there are noted significant errors at Surfaces No. 2 and 3 due to the existence of supports, which were necessary to build at both types of ribs. The centers of the surfaces show negative values of deviations. These are probably caused by the existence of a thin ball feature inside the cube, and the associated insufficient support within the cube, thus there may be some drop in the field. This phenomenon could be confirmed only after cutting a more detailed examination of the interior components.

\section{CONCLUSIONS}

Sintering of metal powder brings many problems which is necessary to identify and consequently to solve. To be 3D printing technology included in the industrial production of the real components, it is required to achieve high qualitative properties of produced parts. Based the facts mentioned above it is clear that final accuracy of a product strongly depend on production speed, part orientation, thickness of layer and necessity of support structures, slice thickness, build orientation and hatching pattern. [19]

The experiments have showed deviations from nominal dimensions as well as the differences between measured values. Observations were carried out at three set of measures. Individual set of measures varied in conditions related to connection of investigated sample with supports and also related to heat treatment.

It can be said that the shrinkage of the parts is very sensitive not only to the technological parameters (component placement, its orientation, print speed thickness of the layer, ...), but also to changes in geometry (thickness of wall, type of the geometrical features, their shapes, etc.). Next factor that affect qualitative parameters is a necessity to build a component with support what strongly influences printing strategies. It is needed to include all the above factors into the process of component production so to be the quality and precision of manufactured part improved.

\section{ACKNOWLEDGMENT}

Paper originates with the direct support of Ministry of Education of Slovak republic by grants VEGA 1/0614/15 and KEGA 087TUKE-4/2015.

\section{REFERENCES}

[1] Ungureanu, M., Pop, N., Ungureanu, N.: Innovation and Technology Transfer for Business Development, Procedia Engineering, Volume 149, (2016), pp. 495-500.

[2] Dobransky, J. et al.: Document Optimization of the production and logistics processes based on computer simulation tools, Key Engineering Materials, 669, (2016), pp. 532-540

[3] Majstorovic, V. et al.: CAI Model for Prismatic Parts in Digital Manufacturing, pp. 27-32, Procedia CIRP, 25 (2014), pp. 27 - 32.

[4] Cloots, M, Spierings A, and Wegener, K.: Assessing new support minimizing strategies for the additive manufacturing technology SLM. Solid Freeform Fabrication Symposium (2013).

[5] Monkova, et al.: Inverse processing of undefined complex shape parts from structural high alloyed tool steel, Advances in Mechanical Engineering (2014), pp. 1-11.
[6] Allen, S. and Dutta, D.: On the computation of part orientation using support structure in layered manufacturing. Solid Freeform Fabrication Symposium, Austin, (1994), pp. 59-269.

[7] Masood, S. H., Rattanawong, W. A Generic Part Orientation System Based on Volumetric Error in Rapid Prototyping. Int. Journal of Advance Manufacturing Technology, 19, (2002) p. 209-216.

[8] Frank, D. and Fadel, G.: Expert system-based selection of the preferred direction of build for rapid prototyping processes. Journal of Intelligent Manufacturing; 6(5), (1995), pp. 339-345.

[9] Pham, D. T. et al.: Orientation in Stereolithography. Int. Journal of Advance Manufacturing Technology, 15 (1999), pp. 674-682.

[10] Hur, S. M., Choi, K. H., Lee, S. H., Chang, P. K.: Determination of fabricating orientation and packing in SLS process. Journal of Material Processing Technology, 112 (2001), pp. 236-243.

[11] Paul, R. and Anand, S.: Optimization of layered manufacturing process for reducing form errors with minimal support structures. doi:10.1016/j.jmsy.2014.06.014, J. of Manuf. Systems (2014).

[12] Valicek, J. et al.: Mechanism of creating the topography of an abrasive water jet cut surface, Advanced Structured Materials, 61, (2016), pp. 111-120.

[13] Baron, P. et al.: Research and application of methods of technical diagnostics for the verification of the design node, Measurement: Journal of the International Measurement Confederation, 94, (2016), pp. 245-253.

[14] Sharma, V. et al.: Surface quality finish in laser cutting using Taguchi design, Technical Gazette, Vol. 4, (2017), pp. 15-19.

[15] Beno, P., Kozak, D., Konjatic, P.: Optimization of thin-walled constructions in CAE system ANSYS, Tehnicki Vjesnik, Volume 21, Issue 5, 1 ( 2014), pp. 1051-1055.

[16] Capkova, V.: Restictive parameters of 3D printing, Diploma thesis, West Bohenia University of Pilsen, 2015.

[17] Hanzl, P., Zetek, M., Zetkova, I.: Cellular Lattice Structure Produced by Selective Laser Melting and its Mechanical Properties, Proceedings of the 26th DAAAM International Symposium, pp.0748-0752, Vienna, Austria (2015)

[18] Summary catalogue, Available online [2017-04-12] http://www.misan.cz/download/conceptlaser/Katalog_Concept_Laser.pdf.

[19] Krehel, R. et al.: Technical diagnostics in the paper industry, Annals of DAAAM and Proceedings of the International DAAAM Symposium, 27(1) (2016), pp. 775-784. 